\title{
Conciliación prejudicial en las acciones de impugnación de las decisiones sociales
}

\author{
Prejudicial conciliation in proceedings \\ for challenging corporate decisions
}

\begin{abstract}
Lina María López Gómez
Abogada y Politóloga

Magíster en Derecho Económico y Especialista en derecho de sociedades Gerente de Asuntos Legales y Recursos Humanos en Condimentos El Rey - Colombia

I_lopez@javeriana.edu.co

Daniela Alvarado Guzmán

Abogada del Grupo Élite contra Colusiones de la Delegatura de Protección de la Competencia de la Superintendencia de Industria y Comercio y, adicionalmente, Actualmente cursa una Especialización en Derecho de la Competencia. alvaradodaniela@javeriana.edu.co
\end{abstract}

\footnotetext{
Cómo citar este artículo:

López, L. M., y Alvarado, D. (2022). Conciliación prejudicial en las acciones de impugnación de las decisiones sociales. Revista de la Facultad de Derecho y Ciencias Políticas, 52(136), pp. 101-123. doi: https://doi.org/10.18566/rfdcp.v52n136.a05

Recibido: 02 de noviembre de 2020

Aprobado: 31 de mayo de 2021
} 


\section{Resumen}

La Ley 640 de 2001 establece la conciliación extrajudicial como requisito de procedibilidad antes de acudir a la jurisdicción civil en procesos declarativos. A través de una metodología cualitativa, el presente artículo tiene como objetivo determinar si los vicios en las decisiones societarias son asuntos susceptibles de conciliación y si se debe agotar la conciliación prejudicial como requisito de procedibilidad para la acción de impugnación de decisiones sociales. Lo anterior para responder a la pregunta de investigación: ¿̇se debe agotar la conciliación como requisito de procedibilidad para la acción de impugnación de decisiones sociales?

Frente a este tema, la jurisprudencia en Colombia ha sido cambiante, adoptando dos posiciones contrarias. La tesis predominante es que la conciliación no es requisito de procedibilidad toda vez que la nulidad y la ineficacia de las decisiones sociales no son materia conciliable por tratarse de asuntos indisponibles en los que está comprometido el orden público.

No obstante, no debe desconocerse que la nulidad puede sanearse por ratificación de las partes (artículo 1742 del Código Civil) y la ocurrencia de las causales de ineficacia puede ser acordada por las partes (artículo 133 de la Ley 446 de 1998). Por lo tanto, a juicio de las autoras de este artículo, sí son asuntos susceptibles de conciliación y debería agotarse la conciliación extrajudicial.

\section{Palabras clave}

Acción de impugnación; conciliación prejudicial; decisiones sociales; ineficacia; nulidad.

\section{Abstract}

Law 640 of 2001 establishes extrajudicial conciliation as a procedural requirement before initiating civil declarative proceedings.

Through a qualitative methodology, this article aims to determine whether the grounds for challenging a corporate decision are a matter subject to conciliation, and whether preliminary conciliation must be fulfilled as a procedural requirement for challenging corporate decisions.

The above to answer the following research question: Should conciliation be fulfilled as a procedural requirement for challenging corporate decisions?

Regarding this topic, the jurisprudence in Colombia has been changing adopting two opposite positions. The prevailing thesis is that conciliation is not a procedural requirement since the nullity and ineffectiveness of corporate decisions are not conciliable matters because they are matters that the parties cannot dispose of, considering that public order is involved. 
However, it should not be ignored that the nullity can be ratified by the parties (article 1742 of the Civil Code) and the occurrence of the causes of ineffectiveness can be agreed upon by the parties (article 133 of Law 446 of 1998).

Therefore, the authors opinion in this article, these are matters subject to conciliation and preliminary conciliation should be fulfilled.

\section{Keywords}

Contestation action, prejudicial conciliation, corporate decisions, ineffectiveness, nullity.

\section{Introducción}

El artículo 38 de la Ley 640 de 2001, modificado por el artículo 621 del Código General del Proceso (Ley 1564 de 2012, C.G.P.), establece que la "conciliación extrajudicial en derecho como requisito de procedibilidad deberá intentarse antes de acudir a la especialidad jurisdiccional civil en los procesos declarativos”. Por tal razón, los objetivos del presente artículo son, en primer lugar, determinar si los vicios en las decisiones societarias son asuntos susceptibles de conciliación. En segundo lugar, establecer, según la jurisprudencia colombiana, si se debe agotar la conciliación prejudicial como requisito de procedibilidad para la acción de impugnación de decisiones sociales.

Frente a la conciliación prejudicial en la impugnación de decisiones de los órganos sociales, la jurisprudencia en Colombia ha sido cambiante adoptando dos posiciones contrarias. Por un lado, una primera tesis defendida por el Tribunal Superior de Bogotá (T.S.B.) en el año 2006 y la Corte Suprema de Justicia (C.S.J.) en el año 2013, 2015 y 2019, estableció que la impugnación de decisiones sociales no era susceptible de conciliación. Según esta teoría, la nulidad y la ineficacia no son materia conciliable por tratarse de asuntos indisponibles en los que estaba comprometido el orden público y que eran ajenos a la voluntad de los interesados.

Por otro lado, una segunda tesis defendida por el Tribunal Superior de Bogotá en el año 2009, según la cual sí se debe agotar la conciliación prejudicial para impugnar decisiones sociales. Dicha teoría encuentra además fundamento en el artículo 1742 del Código Civil en lo que tiene que ver con la nulidad absoluta y en el artículo 133 de la Ley 446 de 1998 en lo relativo a la ineficacia. 
Las posiciones cambiantes de la jurisprudencia colombiana frente a este tema generan incertidumbre para las partes involucradas y su análisis destaca la necesidad de unificar los criterios jurisprudenciales cambiantes. Incluso, son tan graves las consecuencias para los demandantes que deciden agotar la conciliación, que se arriesgan a la caducidad de la acción de impugnación de decisiones sociales si el fallador, adscrito a la primera tesis, considera que la conciliación no es requisito de procedibilidad y que no interrumpe la caducidad de dos meses establecida en la ley (artículo 382 del Código General del Proceso). Allí radica la importancia de presentar en este artículo las dos interpretaciones actualmente existentes que permitan al demandante tomar una decisión informada de los caminos a los que se enfrenta y los riesgos que asume.

En el presente artículo, a través de un método con enfoque cualitativo de tipo hermenéutico, desarrollado a partir de la investigación de estudio de casos y la recopilación documental, se realizará un estudio descriptivo sobre la necesidad, o no, de agotar la conciliación como requisito de procedibilidad para la acción de impugnación de decisiones sociales. Para ello, se profundizará en la jurisprudencia y la normatividad colombiana que soportan los argumentos de las dos tesis ya esbozadas y se presentará una línea jurisprudencial sobre la materia.

La línea jurisprudencial de este artículo ha sido elaborada teniendo en cuenta las técnicas de investigación establecidas por López (2009, p. 168177) donde se identificaron los puntos arquimédicos de apoyo y se realizó una ingeniería reversa para establecer los fallos judiciales anteriores que son citados por las sentencias y los puntos nodales dentro del nicho citacional.

Inicialmente, se hará referencia a la primera tesis. Posteriormente, se analizará la segunda tesis. Finalmente, se presentará la línea jurisprudencial que resume ambas posturas, las conclusiones del estudio y la teoría a la que se adscriben las autoras de este artículo.

\section{Primera tesis: la conciliación no es requisito de procedibilidad para la acción de impugnación de decisiones sociales}

En múltiples años la jurisprudencia del Tribunal Superior de Bogotá y de la Corte Suprema de Justicia ha sostenido que la conciliación prejudicial no es requisito de procedibilidad para la acción de impugnación de decisiones 
sociales. El sustento de lo anterior radica en que la Ley 640 de 2001, que establece la obligatoriedad de la conciliación para asuntos civiles, dispone expresamente que debe tratarse de asuntos susceptibles de transacción y conciliación (artículo 38).

Sin embargo, las normas de orden público no son susceptibles de conciliación y representan una restricción a la autonomía de la voluntad privada, lo cual es aplicable a los vicios de las decisiones sociales (ineficacia, la nulidad y la inoponibilidad) que se derivan de presupuestos taxativamente planteados por la ley (Corte Constitucional, Sentencia C-378 del 23 de abril de 2008). En efecto, el orden público normativo es definido como "el conjunto de normas positivas absolutamente obligatorias, donde no cabe transigencia ni tolerancia, por afectar a los principios fundamentales de la sociedad, de una institución o de las garantías precisas para su subsistencia [...]" (Cabanellas, 1993 citado en Corte Constitucional, Sentencia C-1436 del 25 de octubre de 2000)

Al respecto, según los partidarios de esta primera tesis, la nulidad de las decisiones sociales sobreviene por disposiciones imperativas expresas. Por ende, tratándose de un asunto de orden público le corresponde decidirlo al juez y no a las partes involucradas.

Un claro ejemplo de esto fue la decisión adoptada por el Tribunal Superior de Bogotá en el año 2010. En este caso, se resolvió un recurso de apelación en contra de un auto proferido por el juzgado que rechazó la demanda por no haber agotado la conciliación como requisito de procedibilidad dentro de un proceso de impugnación de decisiones sociales tomadas dentro de una copropiedad. Al respecto, el Tribunal Superior de Bogotá (Auto del 03 de noviembre de 2010) consideró que estaba fuera de discusión que:

[...] a partir de la vigencia de la ley 640 de 2001, si un litigio es susceptible de transacción o de desistimiento (art. 19), antes de acudir al juez civil es necesario que se intente una conciliación extrajudicial, erigida en "requisito de procedibilidad” (art. 35, ib.), al punto que la demanda debe ser rechazada de plano si no se acredita su cumplimiento (artículo 36) [...] (p. 1 y 2).

De esta forma, al estudiar el tema de las asambleas de copropietarios y el contenido de las actas impugnadas en las que se nombran miembros del Consejo de Administración, el Tribunal Superior de Bogotá (Auto del 03 de noviembre de 2010) indicó que la solicitud de nulidad de decisiones adoptadas dentro de este tipo de asambleas no es susceptible de transacción o desistimiento. Para 
esta corporación, el régimen electoral de las copropiedades se encontraba regulado por una norma de orden público. Por lo tanto, no se podría transar o conciliar al respecto, sobre todo porque hacerlo implicaría supeditar un asunto de interés público a la conciliación previa.

Debe señalarse que al exponer la no transigibilidad de la nulidad de decisiones adoptadas en asambleas el T.S.B. (Auto del 03 de noviembre de 2010) no se refiere a las decisiones sociales adoptadas en asambleas de otras formas asociativas, como las sociedades comerciales. El Tribunal solo se pronunció sobre las decisiones adoptadas en asambleas de copropietarios. No obstante, como se verá más adelante, dicho análisis también se extendió desde antes de 2010 en la misma corporación a las decisiones de los órganos de naturaleza societaria.

En el año 2006, el Tribunal Superior de Bogotá ya se había pronunciado frente a la ineficacia del artículo 133 de la Ley 446 de 1998 y del artículo 897 del Código de Comercio (C.Co.) como asuntos no conciliables. A juicio del Tribunal (Sentencia del 28 de septiembre de 2006), la ineficacia es una sanción legal categórica que opera de pleno derecho, de manera que las partes no pueden decidir sobre ello. De esta forma, para el Tribunal (Sentencia del 16 de junio de 2006), al no ser necesario agotar la conciliación como requisito de procedibilidad, esta no interrumpe los términos de caducidad de la acción judicial como pasa a exponerse (Gil Echeverry, 2018, p. 198).

Para profundizar sobre este aspecto, quienes acogen esta tesis afirman que la conciliación que se solicita para la impugnación de decisiones sociales no sirve para interrumpir la caducidad de dos meses establecida en el artículo 191 del Código de Comercio que dispone:

La impugnación sólo podrá ser intentada dentro de los dos meses siguientes a la fecha de la reunión en la cual sean adoptadas las decisiones, a menos que se trate de acuerdos o actos de la asamblea que deban ser inscritos en el registro mercantil, caso en el cual los dos meses se contarán a partir de la fecha de la inscripción.

Igualmente, el artículo 382 del Código General del Proceso, norma posterior que se refiere expresamente a la caducidad, consagra el plazo de dos meses para impugnar: 
La demanda de impugnación de actos o decisiones de asambleas, juntas directivas, juntas de socios o de cualquier otro órgano directivo de personas jurídicas de derecho privado, solo podrá proponerse, so pena de caducidad, dentro de los dos (2) meses siguientes a la fecha del acto respectivo y deberá dirigirse contra la entidad. Si se tratare de acuerdos o actos sujetos a registro, el término se contará desde la fecha de la inscripción [...] (énfasis añadido)

En efecto, en el año 2013 la Corte Suprema de Justicia (Sentencia del 22 de abril de 2013) revisó una tutela contra el Tribunal Superior de Bogotá quien, por su parte, confirmó la decisión de primera instancia de rechazar de plano una demanda de impugnación de decisiones adoptadas en la asamblea de accionistas de una sociedad anónima. El rechazo se dio por considerar que había operado la caducidad, ya que la solicitud de conciliación no era procedente y la demanda se había presentado pasados los dos meses siguientes a la inscripción del acta del máximo órgano social (C.S.J., Sentencia del 9 de noviembre de 2007; Sentencia del 9 de agosto de 2012; y Sentencia del 22 de abril de 2013).

Para la Corte Suprema de Justicia "dado que la nulidad de las decisiones adoptadas en actas de asamblea no son (sic) conciliables" "no se interrumpió la caducidad que corría” (Sentencia del 22 de abril de 2013, p. 7). Para sustentar su argumento citó sentencias de la misma corporación de los años 2007 y 2012. En esta última oportunidad la Corte (Sentencia del 9 de agosto de 2012; Sentencia del 22 de abril de 2013, p. 8) sostuvo que:

La solicitud de conciliación extrajudicial no surtió los efectos suspensivos alegados, debido a que estos solo se predican de los asuntos transigibles, y el presente versa sobre una controversia o discusión que se ha privado de la disposición de los particulares, por voluntad del legislador, dada la trascendencia que para el orden jurídico reviste.

Para analizar el argumento de la Corte conviene hacer una línea de tiempo de la decisión social que fue impugnada hasta llegar a la presentación de la demanda en la siguiente figura: 
Figura 1. Línea de tiempo desde la decisión social hasta la impugnación

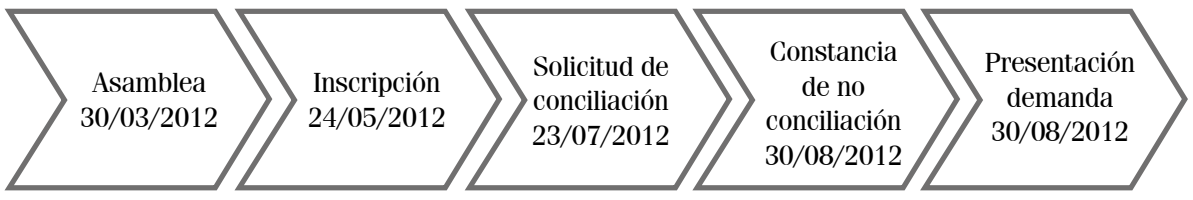

Fuente: Elaboración propia basada en la Sentencia del 22 de abril de 2013 de la Corte Suprema de Justicia

Como se observa, la solicitud de conciliación extrajudicial en este caso fue interpuesta dentro de los dos meses siguientes a la inscripción del acta de asamblea de accionistas. No obstante, para la Corte (Sentencia del 22 de abril de 2013) al no ser procedente la conciliación y al haber sido presentada la demanda el 30 de agosto de 2012, no se suspendió la caducidad y había lugar al rechazo de la demanda.

En gracia de discusión, si se aceptara que la conciliación extrajudicial no es procedente, a juicio de las autoras de este artículo, de todas formas, habría lugar a la interrupción del término de caducidad. El artículo 21 de la Ley 640 de 2001 establece que "la presentación de la solicitud de conciliación extrajudicial en derecho ante el conciliador suspende el término [...] de caducidad" hasta que se expida la constancia a la que se refiere el artículo 2 de esta norma. Uno de los eventos en los que hay lugar a la expedición de dicha constancia es "cuando se presente una solicitud para la celebración de una audiencia de conciliación, y el asunto de que se trate no sea conciliable de conformidad con la ley” (Ley 640 de 2001, artículo 2 numeral 3).

Por lo tanto, la propia norma consagra la posibilidad de solicitar la conciliación extrajudicial para asuntos no conciliables y, se reitera, la primera tesis establece que la nulidad de las decisiones sociales no es susceptible de conciliación. En estos eventos, por expresa disposición legal sí procede la suspensión de la caducidad hasta la expedición de la constancia. Por consiguiente, las autoras consideran que en el caso antes descrito no había lugar al rechazo de la demanda por haber sido presentada dentro del término de dos meses, teniendo en cuenta que dicho término fue suspendido desde la presentación de la solicitud de conciliación 23/07/2012 hasta el 30/08/2012.

A pesar del análisis señalado anteriormente, la Corte Suprema de Justicia reiteró con posterioridad a la sentencia del año 2012, en los años 2013 y 2015, 
que la conciliación extrajudicial, cuando resultaba improcedente, no surtía los efectos de suspensión establecidos en la ley, ya que dicha interrupción solo operaba en los asuntos susceptibles de conciliación (C.S.J., Sentencia del 18 de diciembre de 2013) ${ }^{1}$.

Adicionalmente, en diciembre del año 2013, esta corporación estudió la tutela por vía de hecho contra la sentencia del Tribunal Superior del Distrito Judicial de Villavicencio que conoció de una demanda de impugnación de un acta de asamblea general de copropietarios de una propiedad horizontal. El Tribunal no revocó la decisión del Juzgado Cuarto Civil del Circuito de Villavicencio que había rechazado de plano la demanda porque "no se acreditó la conciliación previa para efecto de la procedibilidad de la acción” (C.S.J., Sentencia del 18 de diciembre de 2013, p. 4).

Para la Corte hubo vía de hecho², es decir, un error mayúsculo en la decisión del juzgador porque el auto que rechazó la demanda no se ajustaba a la ley y era violatorio del debido proceso y el acceso a la justicia. Para la C.S.J. (Sentencia del 18 de diciembre de 2013, p. 7) "no se requiere el agotamiento de la mencionada exigencia procesal en la medida que la nulidad de las decisiones adoptadas en actas de asamblea no son conciliables”. Por tal razón, no se le puede exigir al accionante satisfacer esta carga que no está obligado a asumir. En tal sentido, citó las sentencias de 2007 y abril de 2013 que ya se habían pronunciado sobre la materia, dejó sin efectos el acto impugnado y concedió la tutela (C.S.J., Sentencia del 18 de diciembre de 2013).

Por las mismas razones expresadas en la sentencia de diciembre de 2013 antes reseñada, en otro caso del año 2015, tratándose de la impugnación de actas de la asamblea de copropietarios de un conjunto residencial, la Corte

1 En igual sentido se pronunció el Tribunal Superior de Bogotá (Auto del 11 de diciembre de 2012, p. 3) cuando señaló que "la conciliación previa que se adelantó no sirvió al propósito de interrumpir la caducidad, puesto que las súplicas relativas a la nulidad de las decisiones de elección del nuevo revisor fiscal y de la junta directiva de la sociedad demandada adoptadas en la reunión de asamblea, no son conciliables, máxime si se repara en que no disputan cuestiones como las ya referidas, sino que atañen meramente a temas de carácter imperativo por disposición legal expresa, y a normas de orden público que regulan el régimen societario que, en todo caso, sólo pueden ser dirimidos por el juez".

2 "En los últimos años se ha venido presentando una evolución de la jurisprudencia constitucional acerca de las situaciones que hacen viable la acción de tutela contra providencias judiciales. Este desarrollo ha llevado a concluir que las sentencias judiciales pueden ser atacadas mediante la acción de tutela por causa de otros defectos adicionales, y que, dado que esos nuevos defectos no implican que la sentencia sea necesariamente una "violación flagrante y grosera de la Constitución", es más adecuado utilizar el concepto de "causales genéricas de procedibilidad de la acción" que el de "vía de hecho". Corte Constitucional (Sentencia C-590 del 8 de junio de 2005, párrafo 25). 
Suprema de Justicia revocó un fallo proferido por el Tribunal Superior de Bogotá. El Tribunal había negado en primera instancia la tutela promovida por el accionante contra la providencia proferida por el Juzgado que conoció sobre la acción de impugnación del acta de asamblea general de copropietarios. El Juzgado había considerado que, como no se había agotado la conciliación del artículo 38 de la Ley 640 de 2001, la demanda debía ser rechazada (C.S.J., Sentencia del 12 de marzo de 2015, p. 2).

La accionante impugnó la decisión del Juez señalando que "la impugnación de un acta de asamblea de copropietarios no es un asunto transigible" (C.S.J., Sentencia del 12 de marzo de 2015, p. 2). Adicionalmente, exigir la conciliación como requisito de procedibilidad constituía una vía de hecho, razón por la cual acudió a la tutela.

Al respecto, la Corte Suprema no solo reiteró su jurisprudencia en cuanto a la impertinencia de agotar la conciliación como requisito de procedibilidad en casos de impugnación de decisiones sociales, sino que, además, precisó que se trata de asuntos no conciliables independientemente de si la controversia versa sobre actas de asamblea de copropietarios de un conjunto residencial 0 de sociedades comerciales (C.S.J., Sentencia del 12 de marzo de 2015, p. 5). Para la Corte Suprema la finalidad de ambas acciones es la misma, a saber, lograr la nulidad de las decisiones del máximo órgano social tomadas en desconocimiento de la ley o del régimen de propiedad horizontal.

De esta manera, la Corte (Sentencia del 12 de marzo de 2015, p. 4) advirtió que "el fallador incurrió en una vía de hecho al rechazar de plano la demanda de impugnación de actas de asamblea de copropietarios, por no haberse agotado el requisito de conciliación prejudicial”, revocó la sentencia del Juzgado 65 Civil Municipal de Bogotá impugnada por la accionante y concedió la tutela.

Recientemente, el 14 de enero de 2019, la Corte Suprema de Justicia reiteró lo hasta aquí señalado y negó una tutela contra la decisión del Tribunal Superior de Bogotá de confirmar el rechazo de una demanda contra la decisión de la junta directiva de la sociedad Agroinsumos del Café S.A. por haber operado la caducidad. Esta corporación afirmó que en asuntos de impugnación de decisiones de órganos sociales no es procedente la conciliación "y el hecho de haberse impulsado, ningún efecto comportaría frente a la interrupción de la caducidad de la acción, por lo tanto, el interesado estaba en la obligación de acudir directamente ante la jurisdicción ordinaria para enervar sus pretensiones" (C.S.J., Sentencia del 14 de enero de 2019, p. 6). 
Finalmente, habiendo analizado las sentencias de la jurisdicción civil que se refieren al tema, en la jurisdicción constitucional esta tesis también encuentra soporte en la Sentencia C-378 de 2008 mediante la cual la Corte Constitucional estudió la constitucionalidad del artículo 194 del C.Co. Este artículo -hoy derogado por el artículo 118 de la Ley 1563 de 2012- prohibía que la justicia arbitral conociera las controversias relacionadas con la impugnación de actas de órganos sociales ${ }^{3}$.

En esa oportunidad, la Corte Constitucional (Sentencia C-378 del 23 de abril de 2008, párrafo 33) declaró exequible el artículo 194 y señaló que los "asuntos sometidos a acción de impugnación no son transigibles” por considerar que:

[...] la cautela legal contenida en el artículo 194 demandado según la cual las acciones de impugnación consignadas en las normas citadas habrán de ser ventiladas ante las autoridades judiciales estatales, así se haya pactado previamente cláusula compromisoria, adquiere un sentido específico cual es evitar que las partes de un contrato sometan a transacción aquellos asuntos ligados con la presencia de defectos que cuestionan la validez o la legitimidad de las actuaciones por ellas suscritas. (énfasis añadido)

Por lo tanto, la Corte Constitucional (Sentencia C-378 del 23 de abril de 2008, párrafo 39) reafirmó que la jurisdicción arbitral solo puede conocer los asuntos susceptibles de transacción y reiteró que el artículo 194 "persigue un fin de interés público”, lo que respalda la tesis de que la impugnación de decisiones sociales no puede ser conciliada por las partes sino decidida por el juez. Sin embargo, como se verá más adelante, esta tesis fue replanteada radicalmente por la Corte Constitucional al establecer que las decisiones de asamblea de accionistas o junta directiva constituyen materia arbitrable, cuando estudió la constitucionalidad del artículo 40 de la Ley 1258 de 2008 (Sentencia C-014 del 20 de enero de 2010).

En suma, la primera tesis hasta aquí explicada sostiene que la nulidad e ineficacia de las decisiones sociales son asuntos no susceptibles de decisión por las partes involucradas, quienes no pueden conciliar ni decidir sobre la ocurrencia o no de las causales establecidas en la ley que son de orden público.

3 Artículo 194 del C.Co.: "Las acciones de impugnación previstas en este Capítulo se intentarán ante los jueces, aunque se haya pactado cláusula compromisoria, y se tramitarán como se dispone en este mismo Código y, en su defecto, en la forma prevista en el Código de Procedimiento Civil para los procesos abreviados". 
Por tal motivo, si se solicita la conciliación como requisito de procedibilidad y transcurren los dos meses siguientes a la fecha del acto respectivo, o a la fecha de la inscripción si se trata de actos sujetos a registro, habrá operado la caducidad de la acción (artículo 191 del Código de Comercio y artículo 382 del Código General del Proceso).

En este aparte se explicaron los argumentos por los cuales se afirma que la conciliación no es requisito de procedibilidad para la impugnación de decisiones sociales. No obstante, como pasará a desarrollarse, esta tesis no está exenta de críticas y decisiones que la contrarían.

\section{Segunda tesis: la conciliación sí es requisito de procedibilidad para la acción de impugnación de decisiones sociales}

Pese a lo reiterado por los Tribunales Superiores y la Corte Suprema de Justicia en los pronunciamientos antes estudiados donde sostienen que la nulidad absoluta es un asunto indisponible por estar comprometido el orden público y, pese a la falsa creencia de que la nulidad absoluta no es subsanable, a continuación se procederá a exponer los argumentos de la tesis según la cual la nulidad absoluta y la ineficacia sí son susceptibles de conciliación.

En lo que tiene que ver con la nulidad absoluta, el artículo 1742 del Código Civil establece expresamente la posibilidad de sanearla de dos formas cuando no ha sido ocasionada por causa u objeto ilícito: la primera, por ratificación de las partes y, la segunda, por prescripción extraordinaria. Tal como señala el artículo 1742:

La nulidad absoluta puede y debe ser declarada por el juez, aún sin petición de parte, cuando aparezca de manifiesto en el acto o contrato; puede alegarse por todo el que tenga interés en ello; puede así mismo pedirse su declaración por el Ministerio Público en el interés de la moral o de la ley.

Cuando no es generada por objeto o causa ilícitos, puede sanearse por la ratificación de las partes y en todo caso por prescripción extraordinaria. (énfasis añadido).

Lo anterior, permite afirmar que las partes pueden conciliar tratándose de nulidades absolutas cuyo origen haya sido diferente a la causa u objeto ilícito 
como podría suceder en los demás casos previstos en el artículo 1741 del mismo Código y que causan dicha clase de nulidad (Gil Echeverry, 2018, p. 183-191).

Para las autoras de este artículo, es claro que con la redacción del Código Civil (artículo 1742) el legislador estableció la posibilidad de que las partes involucradas dentro de una relación jurídica viciada por nulidad absoluta generada por una circunstancia diferente al objeto y la causa ilícita puedan sanearla por ratificación o por el acaecimiento de la prescripción extraordinaria (Corte Constitucional, Sentencia C-345 del 24 de mayo de 2017).

De esta manera, a partir de la definición y las características de la conciliación extrajudicial como método alternativo de resolución de conflictos y de la interpretación que la Corte Constitucional (Sentencia C-893 del 22 de agosto de 2001) le ha dado, es claro que esta constituye una de las tantas formas a través de las cuales dos o más sujetos se pueden poner de acuerdo o ratificar una actuación y/o decisión.

Por lo tanto, a pesar de no ser el único método a través del cual se puede lograr un acuerdo entre las partes, la conciliación resulta ser un mecanismo idóneo para obtener la ratificación señalada por el legislador en el artículo 1742 del Código Civil. En ese sentido, son conciliables los asuntos previstos en el artículo 1741, diferentes al objeto y causa ilícita, cuyo acaecimiento genera nulidad absoluta.

Adicionalmente, en el artículo 38 de la Ley 640 de 2001, modificado por el Código General del Proceso, el legislador dispuso que "si la materia de que trate es conciliable, la conciliación extrajudicial en derecho como requisito de procedibilidad deberá intentarse antes de acudir a la especialidad jurisdiccional civil en los procesos declarativos”. Por consiguiente, si la nulidad absoluta es conciliable, salvo en los casos ya expuestos, se deberá agotar dicho requisito para la impugnación de decisiones sociales (Gil Echeverry, 2011, p. 86-89).

Ahora bien, en lo que se refiere a la impugnación de decisiones sociales por ineficacia también es un asunto conciliable y, en consecuencia, debería agotarse el requisito de procedibilidad de la Ley 640 de 2001. En efecto, el artículo 133 de la Ley 446 de 1998 dispone que las partes pueden ponerse de acuerdo sobre la ocurrencia de las causales de ineficacia. El texto del artículo 133, posteriormente incorporado en el artículo 326 del Estatuto Orgánico del Sistema Financiero, señala: 
8. Del ejercicio de funciones jurisdiccionales por las Superintendencias. Del reconocimiento de la Ineficacia. Competencia: Sin perjuicio de lo previsto en el artículo 897 del Código de Comercio, las Superintendencias Bancaria, de Sociedades o de Valores podrán de oficio efectuar el reconocimiento de los presupuestos de ineficacia previstos en el Libro Segundo del Código de Comercio. Así mismo, a falta de acuerdo de las partes sobre la ocurrencia de dichas causales de ineficacia, podrá una de ellas solicitar a la respectiva Superintendencia su reconocimiento. En relación con las sociedades no vigiladas permanentemente por las referidas entidades, tal función será asumida por la Superintendencia de Sociedades. (énfasis añadido).

Por lo tanto, de la literalidad de la norma se concluye que es un asunto susceptible de conciliación porque incluso las partes en una reunión posterior pueden ratificar la decisión ineficaz, tal como lo ha manifestado la Superintendencia de Sociedades (Oficio No. 320-44695 de 2000), al reconocer que "es legalmente viable la ratificación de la decisión [ineficaz] mediante una decisión otra vez adoptada por la totalidad de los asociados, bien sea en una reunión universal o en una reunión convocada para tal efecto”.

Adicionalmente, aunque la ineficacia no requiere declaración judicial, a falta de acuerdo entre los interesados la Superintendencia de Sociedades puede reconocer, de oficio o a solicitud de parte, que se dieron los presupuestos que originan esa sanción. Por un lado, el parágrafo primero del artículo 87 de la Ley 222 de 1995 establece que la competencia de la Superintendencia de Sociedades para reconocer de oficio los presupuestos de ineficacia en los casos señalados en el Libro II del Código de Comercio será en ejercicio de sus facultades administrativas.

Por otro lado, las solicitudes de parte que se reciban para el reconocimiento de los presupuestos de ineficacia son una facultad jurisdiccional, de conformidad con lo dispuesto en el artículo 133 de la Ley 446, el cual otorgó esa facultad jurisdiccional a la Superintendencia de Sociedades, sin desconocer que la ineficacia opera de pleno derecho. Por ende, siendo la ineficacia un asunto conciliable entre las partes, la conciliación extrajudicial en derecho es requisito de procedibilidad y deberá intentarse antes de acudir a la jurisdicción de la Superintendencia de Sociedades tal como lo establece el artículo 38 de la Ley 640 de 2001.

Al respecto, dos providencias del año 2009 del Tribunal Superior de Bogotá ilustran la procedencia de la conciliación como requisito de procedibilidad en la nulidad e ineficacia de las decisiones sociales: los casos de Diego Fernando 
Delgado Martínez contra Bavaria S.A. del 6 de mayo de 2009 y de Edith Rocío Albarracín Hernández contra Famalba S.A. del 21 de agosto del mismo año.

En la primera providencia, el señor Delgado Martínez acudió a la jurisdicción ordinaria solicitando la declaración de ineficacia ${ }^{4}$ de la asamblea de accionistas de la compañía Bavaria S.A. por considerar que el Revisor Fiscal no dio cumplimiento a la obligación que le impone el artículo 432 del C.Co., consistente en enviar a la Superintendencia "dentro de los quince días siguientes al de la reunión, copia autorizada del acta de la respectiva asamblea”. La sociedad demandada formuló recurso contra el auto admisorio de la demanda por no haberse agotado la conciliación como requisito de procedibilidad. El juzgado resolvió el recurso y rechazó la demanda, ante lo cual el demandante impugnó en reposición y subsidio apelación y esta última llegó a conocimiento del Tribunal Superior de Bogotá.

El Tribunal Superior señaló que el problema jurídico consistía en “determinar si la materia objeto de controversia, y que fuere planteada en la pretensión principal, es susceptible de transacción, desistimiento y conciliación" (Auto del 6 de mayo de 2009, p. 2) de conformidad con los artículos 19 y 38 de la Ley 640 de 2001. Al decidir la cuestión, esta corporación confirmó el auto que rechazó la demanda y determinó que:

En conclusión, nada imposibilita a las partes llegar a un acuerdo relacionado con sus diferencias, y por ende, conciliar las mismas sin necesidad de acudir a la jurisdicción ordinaria, por lo que, resulta procedente la exigencia del requisito de procedibilidad establecido en el artículo 38 de la Ley 640 de 2001, pues, el conflicto expuesto, como se dijo es susceptible de conciliación, en el entendido de intentar un acuerdo relativo a la existencia o no de la causal alegada como fundamento de la ineficacia peticionada en la pretensión principal. (énfasis añadido) (T.S.B., Auto del 6 de mayo de 2009, p. 4).

No obstante, debe aclararse que el Tribunal señaló que, como la pretensión principal radicaba en la ineficacia por no haberse enviado por parte del Revisor Fiscal copia del acta a la Superintendencia, esta controversia resultaba susceptible de conciliación "toda vez que, en principio no se estarían atacando las decisiones tomadas en la Asamblea General Ordinaria de Accionistas de Bavaria S.A." (Auto del 6 de mayo de 2009, p. 4).

$4 \quad$ El artículo 433 del Código de Comercio establece que "serán ineficaces las decisiones adoptadas por la asamblea en contravención a las reglas prescritas en esta Sección". 
Frente a esto, debe advertirse que el Tribunal no fue contundente al señalar que todas las causales de ineficacia son susceptibles de conciliación ya que, al conceder el recurso impetrado, consideró que la controversia no constituía un presupuesto de ineficacia por no referirse a una de las situaciones contenidas en el artículo 190 del C.Co. ${ }^{5}$, a pesar de que el artículo 433 del C.Co. antes citado también se refiere a la ineficacia. Además, el Tribunal (Auto del 6 de mayo de 2009) afirmó que el asunto objeto de estudio sí podía ser conciliable porque no se atacaban decisiones tomadas en la asamblea de accionistas al ser un asunto referido al envío del acta a la Superintendencia.

En la segunda providencia, el Tribunal Superior de Bogotá resolvió un recurso de apelación formulado por el accionante contra el auto de rechazo de la demanda de impugnación de decisiones sociales de la sociedad Famalba S.A. proferido por el Juzgado Tercero Civil del Circuito que conoció del proceso.

En el proceso iniciado el 17 de octubre de 2008, el accionante solicitó al juzgado "que se declare la ineficacia, la inexistencia o en subsidio la nulidad" de dos actas de la Asamblea General de Accionistas de la sociedad Famalba (T.S.B., Auto del 21 de agosto de 2009, p. 1).

Al respecto, el juzgado de primera instancia señaló que había operado la caducidad de la acción por no haberse interpuesto la demanda dentro de los dos meses siguientes a la fecha del acto respectivo o de la inscripción si se trata de un asunto sujeto a registro (artículo 421 del C.Co.). Asimismo, para el juzgado la conciliación prejudicial celebrada no interrumpió el término de caducidad por tratarse de un asunto no susceptible de conciliación (T.S.B., Auto del 21 de agosto de 2009, p. 2).

Pese a lo afirmado por el juzgado, el Tribunal (Auto del 21 de agosto de 2009 , p. 3) reiteró su postura ${ }^{6}$ y revocó el auto recurrido que había rechazado la demanda y a buen juicio de las autoras de este artículo indicó:

5 El artículo 190 del Código de Comercio dispone: "Las decisiones tomadas en una reunión celebrada en contravención a lo prescrito en el artículo 186 serán ineficaces; las que se adopten sin el número de votos previstos en los estatutos o en las leyes, o excediendo los límites del contrato social, serán absolutamente nulas; y las que no tengan carácter general, conforme a lo previsto en el artículo 188 , serán inoponibles a los socios ausentes o disidentes".

6 En una decisión anterior el T.S.B. había señalado: "Puestas de este modo las cosas, se concluye que el juez no podía rechazar de plano la demanda, so pretexto de aducir que las pretensiones de la demanda no fueren susceptibles de conciliación y, de allí, descartar la interrupción del término de caducidad para instaurarla, lo que traduce que la conciliación realizada ciertamente, en estrictez, tenía el carácter legal de ampliar el término para impetrar la acción intentada, habida cuenta que el asunto objeto de controversia contaba con la posibilidad de dirimirse mediante el referido mecanismo de solución de conflictos". T.S.B., Sala Civil (2009). Bogotá. Providencia del 24 de abril de 2009. 
No obstante lo anterior, cuando en un proceso se pretende aniquilar o relativizar los efectos de una decisión social, ese objeto pretensional si (sic) puede ser motivo de transacción, no para imponer requisitos de legalidad diversos a los que señala el dador de la ley de manera imperativa, sino para resolver ese conflicto en el umbral mismo de la actuación, al convenirse sobre la no concurrencia de los efectos regulados para el valor del acto y proceder en virtud de un acuerdo en ese sentido a corregir desde ese momento -sin necesidad de sentencia que lo declare- los defectos enrostrados[...] (énfasis añadido).

De esta manera, sin desconocer que los presupuestos que dan lugar a la sanción de ineficacia dentro de la ley son de orden público, para el Tribunal (Auto del 21 de agosto de 2009) la pretensión de la demanda se puede solucionar si por medio de un acuerdo conciliatorio, las partes reconocen el acaecimiento de la ineficacia del acto social y despliegan conductas encaminadas a sanearla y/o ratificarla.

Con buen criterio el Tribunal (Auto del 21 de agosto de 2009, p. 4) concluyó que "la conciliación realizada, en estrictez, tenía el carácter legal de ampliar el término para impetrar la acción intentada, habida cuenta que el asunto objeto de controversia contaba con la posibilidad de dirimirse mediante el referido mecanismo de solución de conflictos”. Por lo tanto, la demanda fue presentada por el accionante de forma previa al vencimiento del término de los dos meses que tenía para hacerlo.

En la jurisdicción constitucional también se encuentran argumentos a favor de la segunda tesis que se expone. En efecto, en la sentencia C-014 de 2010 la Corte Constitucional declaró exequible el artículo 40 de la Ley 1258 de $2008^{7}$ y cambió su jurisprudencia frente a lo afirmado previamente en la sentencia C-378 de 2008, tal como lo reconoce la aclaración de voto del magistrado Luis Ernesto Vargas ${ }^{8}$.

$7 \quad$ Ley 1258 de 2008, artículo 40. Resolución de conflictos societarios. "Las diferencias que ocurran a los accionistas entre sí, o con la sociedad o sus administradores, en desarrollo del contrato social o del acto unilateral, incluida la impugnación de determinaciones de asamblea o junta directiva con fundamento en cualquiera de las causas legales, podrán someterse a decisión arbitral o de amigables componedores, si así se pacta en los estatutos. Si no se pacta arbitramento o amigable composición, se entenderá que todos los conflictos antes mencionados serán resueltos por la Superintendencia de Sociedades, mediante el trámite del proceso verbal sumario".

8 El magistrado Luis Ernesto Vargas señaló: “...considero conveniente aclarar que esta sentencia implica un cambio de la jurisprudencia de la Corte, sentada en sentencias C-378 de 2008 y SU 174 de 2007, en cuanto al carácter transigible de los asuntos que pueden someterse a tribunal de arbitramento, lo cual se explica por la modificación que sufrió el artículo 13 de la Ley Estatutaria de 
En el año 2010, la Corte Constitucional afirmó que la Ley 1285 de 2009 eliminó el requisito de que solo los asuntos susceptibles de transacción pueden ser conocidos por la jurisdicción arbitral y agregó que el legislador puede disponer que un asunto comercial deje de ser considerado como de orden público para ser resuelto mediante mecanismos alternativos de solución de conflictos como la conciliación. Esta corporación señaló (Sentencia C-014 del 20 de enero de 2010, párr. 3.4.2):

3.4.2. De este análisis se deriva para el caso concreto lo siguiente: en su momento se consideró que la impugnación de decisiones de la asamblea 0 junta de socios de las sociedades tipificadas en el Código de Comercio debía necesariamente tramitarse ante los jueces, aunque se hubiese pactado cláusula compromisoria, porque dada su importancia se le percibía como un asunto no susceptible de transacción. Frente al nuevo tipo societario conocido como Sociedad por Acciones Simplificada, se tiene que el requisito estatutario según el cual los asuntos sometidos a decisión arbitral sólo pueden ser aquellos susceptibles de transacción ha sido modificado en la Ley 1285 de 2009. Pero además, es perfectamente posible que el Legislador considere que dicha materia, del ámbito de las relaciones comerciales, deje de ser considerada asunto de orden público y se permita discutir y resolver en el ámbito de la autonomía de la voluntad y los MASC, de pactarse en los estatutos de las SAS. (énfasis añadido)

Posteriormente, en el año 2018 la Corte Suprema de Justicia resolvió un recurso de queja presentado por el accionante contra una sentencia del T.S.B. que rechazó el recurso de casación dentro de un proceso de impugnación de las decisiones tomadas en la asamblea de copropietarios del Edificio Carlina - Propiedad Horizontal. En la descripción de los antecedentes que hizo la C.S.J. (Auto del 2 de mayo de 2018) sobre el trámite que tuvo el proceso para la impugnación de dichas decisiones, se puede evidenciar que cuando el accionante presentó en un primer momento la demanda de nulidad, esta fue rechazada por no haber agotado la conciliación.

Lo interesante de este caso radica en que, en su momento, el T.S.B. revocó el auto de rechazo de la demanda, pero no bajo el argumento de que la conciliación fuera obligatoria o no para acudir a la jurisdicción y en ese sentido

\footnotetext{
la Justicia, por la Ley 1285 de 2009, en la cual no se exige la transigibilidad de los asuntos". No obstante, las autoras del presente artículo destacan que la Constitución Política de Colombia es la misma, por lo que la modificación en una ley estatutaria no debería cambiar la postura de la Corte Constitucional.
} 
si existía o no el deber de agotarla, sino que se basó en que las pretensiones no tenían contenido económico y, por lo tanto, no era necesario agotarla (C.S.J., Auto del 2 de mayo de 2018).

A juicio de las autoras de este artículo, se puede evidenciar que el Tribunal Superior de Bogotá no solo ha desarrollado las dos posturas expuestas a lo largo del escrito, sino que ha tenido una postura según la cual, si la impugnación de la decisión que se pretende no lleva implícito un contenido económico o el accionante no persigue un interés de dicha naturaleza, entonces no es necesario agotar la conciliación.

Esta postura adoptada por el Tribunal resulta cuestionable, en la medida que el legislador no hizo alguna distinción o estableció alguna limitación sobre el contenido económico en las materias de las que trata el artículo 38 de la Ley 640 de 2001 y, además, tratándose del desarrollo jurisprudencial de la posibilidad de conciliar la nulidad o ineficacia de las decisiones sociales, el criterio económico no ha sido determinante para establecer la procedencia de la conciliación como requisito de procedibilidad.

En opinión de las autoras de este artículo, resulta claro que la demanda de impugnación de una decisión, independientemente de que se trate de una sociedad o de una copropiedad, no lleva consigo necesariamente una pretensión económica en el sentido de reclamar una suma de dinero, por lo que no debería tenerse en cuenta si las pretensiones tienen contenido económico para estudiar la procedencia de la conciliación extrajudicial.

Por lo tanto, para decidir si era necesario agotar la conciliación, el Tribunal debió haberse apartado de si el contenido de la impugnación o el interés que se perseguía con esta era económico y, por el contrario, examinar si las causales que dieron origen a la nulidad de las decisiones podían o no conciliarse y en esa medida hacer exigible el requisito de procedibilidad a la luz del artículo 38 de la Ley 640 de 2001.

En conclusión, la segunda tesis sostiene que la nulidad e ineficacia de las decisiones societarias son asuntos susceptibles de conciliación por las partes involucradas quienes pueden decidir sobre la ocurrencia de las causales establecidas en la ley e incluso pueden ratificar las decisiones nulas o ineficaces tomadas previamente. Por tal motivo, a la luz de esta tesis, resulta procedente, conforme con el artículo 38 de la Ley 640 de 2001, exigir la conciliación como requisito de procedibilidad de la acción de impugnación. 
En la tabla presentada a continuación se observa la línea jurisprudencial que se ha desarrollado a lo largo del presente artículo, elaborada teniendo en cuenta la metodología de tres pasos de López (2009, p. 168-177): puntos arquimédicos de apoyo; ingeniería reversa y puntos nodales de jurisprudencia.

Tabla 1. Línea Jurisprudencial; ¿Se debe agotar la conciliación como requisito de procedibilidad para la acción de impugnación de decisiones sociales?

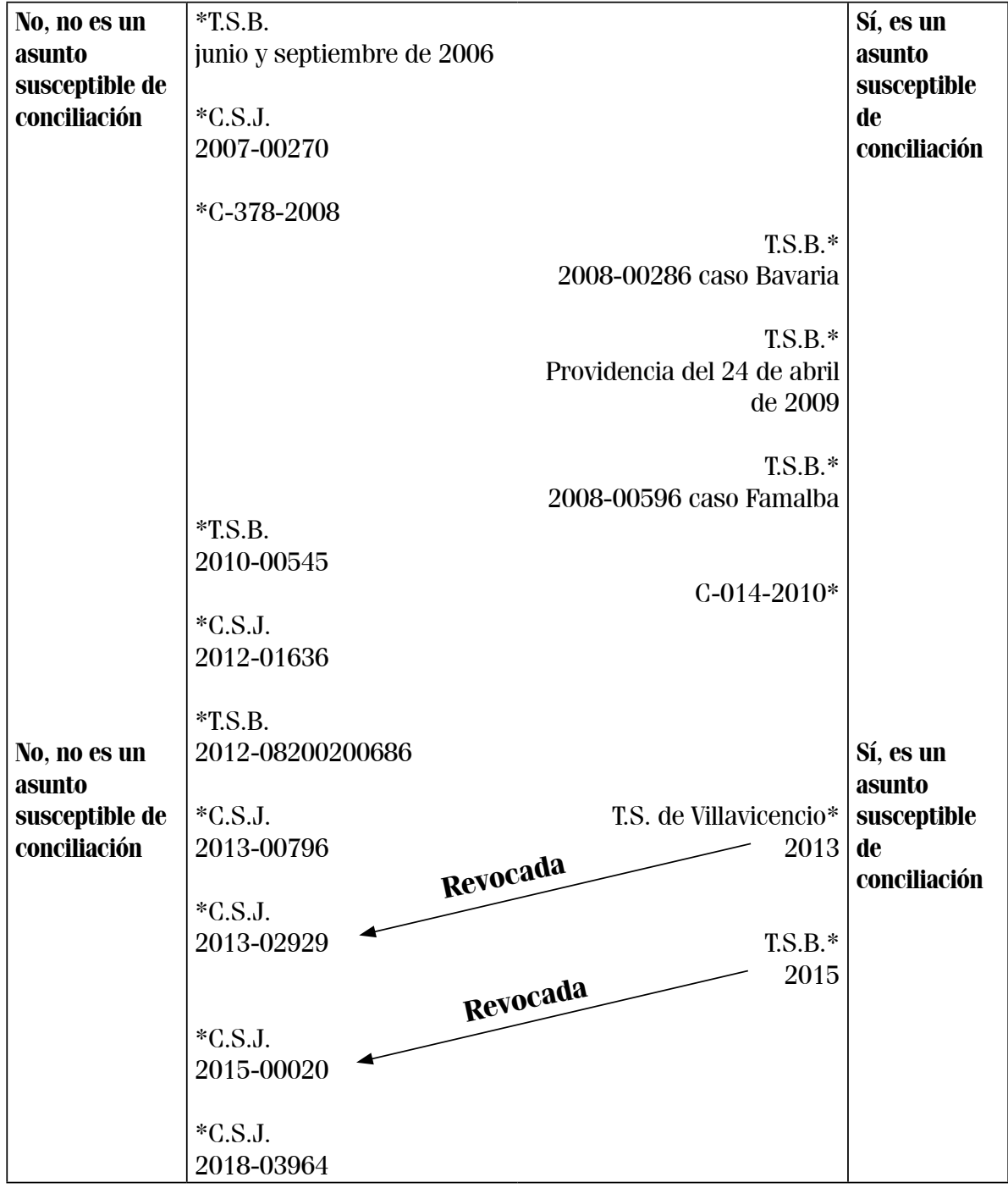

Fuente: Elaboración propia. 


\section{Conclusión}

El presente artículo expuso la jurisprudencia frente a la conciliación como requisito de procedibilidad para la impugnación de decisiones sociales. Como se observó, no es un asunto pacífico y la jurisprudencia de la Corte Suprema de Justicia ha estado encaminada, incluso en una decisión reciente del año 2019, a establecer que la nulidad y la ineficacia de las decisiones de los órganos de naturaleza societaria no son susceptibles de conciliación por ser ajenas a la voluntad de las partes y por tratarse de asuntos donde está comprometido el orden público de manera que solo el juez puede decidir sobre ellos. De esta forma, para la Corte, la conciliación intentada no interrumpe la caducidad de la acción. En definitiva, esta es la tesis predominante en la jurisprudencia colombiana.

No obstante, se advierte que las autoras del presente artículo se adhieren a la segunda tesis ya expuesta, ya que no debe desconocerse que la nulidad, por virtud del artículo 1742 del Código Civil, puede sanearse, cuando no ha sido ocasionada por causa u objeto ilícito, por ratificación de las partes. Adicionalmente, la ocurrencia de las causales de ineficacia, conforme con el artículo 133 de la Ley 446 de 1998, puede ser acordada por las partes. Por lo tanto, la conciliación extrajudicial sí debe ser un requisito de procedibilidad de la acción de impugnación y con esta se interrumpe el término de caducidad de la acción.

Asimismo, se destaca que promover los mecanismos alternativos de solución de conflictos, como la conciliación prejudicial, disminuye la congestión judicial que para el año 2019 era del 50.75\% según el índice de congestión efectiva, por lo que 50 de cada 100 procesos quedaron pendientes para trámite (Contraloría General de la República, 2019).

El presente artículo demostró la incertidumbre que existe en la actualidad para las partes involucradas en estos procesos, ante la falta de claridad de la postura que asumirá el juez al estudiar y decidir el caso. Las autoras llaman la atención sobre la necesidad de unificar los criterios jurisprudenciales cambiantes dadas las graves consecuencias para los demandantes que deciden agotar la conciliación, que se arriesgan incluso a la caducidad de la acción si el fallador, adscrito a la primera tesis, considera que la conciliación no es requisito de procedibilidad y que no interrumpe la caducidad de dos meses establecida en la ley. Este artículo presentó las dos interpretaciones de la jurisprudencia lo que le permitirá al demandante tomar una decisión informada de los caminos a los que se enfrenta y los riesgos que asume. 
Teniendo en cuenta las variaciones jurisprudenciales hasta aquí reseñadas y los argumentos a favor de cada postura, para evitar de plano el rechazo de la demanda, se recomienda presentar la demanda correspondiente junto con la solicitud de medidas cautelares ${ }^{9}$ siempre que estas sean procedentes, para no tener que agotar la conciliación como requisito de procedibilidad y no arriesgarse a la caducidad de la acción. Lo anterior amparado en el parágrafo primero del artículo 590 del Código General del Proceso que establece que "en todo proceso y ante cualquier jurisdicción, cuando se solicite la práctica de medidas cautelares se podrá acudir directamente al juez, sin necesidad de agotar la conciliación prejudicial como requisito de procedibilidad”.

\section{Referencias}

Cabanellas, G. (1993). Diccionario Enciclopédico de Derecho Usual. Buenos Aires: Heliasta.

Colombia. Congreso de la República (12 de julio de 2012). Código General del Proceso, Ley 1564 de 2012, Diario Oficial No. 48.489.

Colombia. Congreso de la República (12 de julio de 2012). Ley 1563 de 2012, Diario Oficial No. 48.489.

Colombia. Congreso de la República (8 de julio de 1998). Ley 446 de 1998, Diario Oficial No. 43.335.

Colombia. Congreso de la República (24 de enero de 2001). Ley 640 de 2001, Diario Oficial No. 44.303.

Colombia. Presidente de la República de Colombia, en ejercicio de facultades extraordinarias (5 de abril de 1993). Estatuto Orgánico del Sistema Financiero, Decreto Ley 663 de 1993, Diario Oficial No. 40.820.

Colombia. Presidente de la República de Colombia, en ejercicio de facultades extraordinarias (16 de junio de 1971). Código de Comercio, Decreto 410 de 1971, Diario Oficial No. 33.339.

Contraloría General de la República (2019). Congestión judicial en Colombia es del 50\%, según la Contraloría. Recuperado el 22 de mayo de 2021 dehttps://

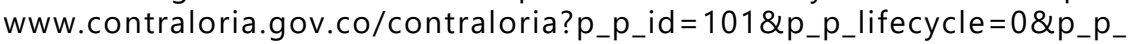
state $=$ maximized $\&$ p_p_mode $=$ view $\&$ _ 101 _struts_action $=\% 2$ Fasset_ publisher\%2Fview_content $\&$ _101_returnToFullPageURL=https\%3A\%2F\%2Fw ww.contraloria.gov.co\%3A443\%2Fcontraloria\%3Fp_auth\%3DznOA1eVx\%26p_p_ id\%3D3\%26p_p_lifecycle\%3D1\%26p_p_state\%3Dnormal\%26p_p_state_ rcv\%3D1\&_101_assetEntryld $=1890330 \& \_101$ type $=$ content $\&_{-} 101$ _ urlTitle=elnuevosiglo-com-co-congestion-judicial-en-colombia-es-del-50-segunla-contraloria\&inheritRedirect=true

$9 \quad$ Una de las medidas cautelares que se pueden solicitar es la suspensión provisional de los efectos del acto impugnado tal como lo establece el artículo 382 del Código General del Proceso. 
Corte Constitucional (25 de octubre de 2000). Sentencia C-1436. [MP. Alfredo Beltrán Sierra]

Corte Constitucional. (8 de junio de 2005). Sentencia C-590. [MP. Jaime Córdoba Triviño]

Corte Constitucional. (23 de abril de 2008). Sentencia C-378. [MP. Humberto Sierra Porto]

Corte Constitucional. (20 de enero de 2010). Sentencia C-014. [MP. Mauricio González Cuervo]

Corte Constitucional. (22 de agosto de 2001). Sentencia C-893. [MP. Clara Inés Vargas Hernández]

Corte Suprema de Justicia, Sala de Casación Civil. (9 de noviembre de 2007). Sentencia, expediente 00270-01.

Corte Suprema de Justicia, Sala de Casación Civil (9 de agosto de 2012). Sentencia, expediente 01636-00.

Corte Suprema de Justicia, Sala de Casación Civil. (22 de abril de 2013). Sentencia, expediente 11001-02-03-000-2013-00796-00. [MP. Margarita Cabello Blanco]

Corte Suprema de Justicia, Sala de Casación Civil. (18 de diciembre de 2013). Sentencia, expediente 11001-02-03-000-2013-02929-00. [MP: Fernando Giraldo Gutiérrez]

Corte Suprema de Justicia, Sala de Casación Civil. (12 de marzo de 2015). Sentencia, expediente 11001-22-03-000-2015-00020-01. [MP. Ariel Salazar Ramírez]

Corte Constitucional. (24 de mayo de 2017). Sentencia C-345. [MP. Alejandro Linares Cantillo]

Corte Suprema de Justicia, Sala de Casación Civil. (2 de mayo de 2018). Auto, expediente 11001-02-03-000-2018-00256-00. [MP. Margarita Cabello Blanco]

Corte Suprema de Justicia, Sala de Casación Civil. (14 de enero de 2019). Sentencia, radicación 11001-02-03-000-2018-03964-00. [MP. Luis Armando Tolosa Villabona]

Gil Echeverry, J. H. (2011). La conciliación extrajudicial y la amigable composición. Bogotá: Temis.

Gil Echeverry, J. H. (2012). Impugnación de decisiones societarias. Bogotá: Legis.

Gil Echeverry, J. H. (2018). La nulidad absoluta en contratación mercantil. Bogotá: Legis. López Medina, D. E. (2009). La línea jurisprudencial: análisis dinámico de precedentes. En: El derecho de los jueces: obligatoriedad del precedente constitucional, análisis de sentencias y líneas jurisprudenciales y teoría del derecho judicial (p. 139-192). Bogotá: Legis.

Superintendencia de Sociedades. (13 de julio de 2000). Oficio No. 320-44695.

Tribunal Superior de Bogotá, Sala Civil. (16 de junio de 2006). Sentencia.

Tribunal Superior de Bogotá, Sala Civil. (28 de septiembre de 2006). Sentencia. [MP. Myriam Inés Lizarazu]

Tribunal Superior de Bogotá, Sala Civil (6 de mayo de 2009). Auto, radicación 200800286-01. [MP. Ariel Salazar Ramírez]

Tribunal Superior de Bogotá, Sala Civil. (21 de agosto de 2009). Bogotá. Auto, radicado 1100131030003200800596-01. [MP. Luis Roberto Suárez González]

Tribunal Superior de Bogotá, Sala Civil. (03 de noviembre de 2010). Bogotá. Auto, expediente 17201000545-01. [MP. Marco Antonio Álvarez Gómez]

Tribunal Superior de Bogotá, Sala Civil. (11 de diciembre de 2012). Auto, expediente 08200200686 02. [MP. Marcela Adriana Castillo Silva] 